\title{
A GENERAL SCIENCE COURSE OF ELEMENTARY PHYSICS AND MATHEMATICS COMBINED.
}

\author{
By J. C. Gray, \\ Thornton Academy, Saco, Maine.
}

Along with the other suggestions for a general science course which have appeared in this magazine the writer offers the following, believing that only by discussion and exchange of ideas can a general science course be developed such as will be generally accepted. His suggestion is for a course of elementary physics and mathematics combined, so that each subject will furnish material for the other, thus securing a suitable correlation of the science and mathematics, which will help the pupil in each. This course in general science is given in the second year, five times a week, following the first year algebra. It is followed in the third year by chemistry, and in the fourth year by physics for those going to college and by applied science for those not going. This course and this order of chemistry and physics has just been started at Thornton Academy, so it is yet too early to judge of the results.

Most science teachers now recognize the need of an introductory science course, but differ in what its content should be. Some believe that such a course should teach a little about every science which the pupil is likely to study in the high school: chemistry, physics, physical geography, botany, zoölogy, and even physiology; others that it should be based on physical geography or agriculture and journey into physics or chemistry for explanation of phenomena. But the chief objection to such courses in general science is that they just skim the surface of the subject without giving the pupil much of real educational value. To be of real benefit to the pupil an efficient general science course must develop his mental abilities, as well as give the elements on which to base further work in science. Both of these purposes can best be served by taking up in a thorough manner a few subjects in physics, which are to be most used later, with experiments, problems, explanations, and applications. The experiments teach the pupil how to measure and to weigh carefully and to record data in the notebook, as well as furnishing material for the problem work. The problems, if carefully chosen, give the opportunity to apply algebra and geometry, the uses of which in science always trouble pupils. The explanations and applications of the subjects studied give the fundamental facts to be used in further science study. 
Aside from the general objects of high school science courses as usually stated, namely, (I) to develop the pupil's powers of observation and of reasoning, (2) to train him in methods of scientific work and expression, and (3) to extend his knowledge of scientific subjects, this general science course may be said to have for its specific objects ( 1 ) to lay a firm foundation for further work in science and (2) to help the pupil who finds mathematics hard.

In attempting to carry out the first of these objects, to lay a firm foundation for further work in science, such topics in physics are taken up as are most useful for work in chemistry the next year, or as furnish good problems for applications of mathematics. Some of these topics are the metric system, measuring and weighing, density, specific gravity, measurement of temperature and of pressure, Charles' and Boyle's Laws, states of matter, melting and boiling points, Ohm's Law, polarity, etc.

In attempting to carry out the second of these objects, to help the pupil who finds mathematics hard, the work is not taken up in any logical order, but algebra and geometry are brought in as they are needed in the work in physics; that is, the pupil finds some need for algebra or geometry in working out some problem, before he is given the mathematical principle to use. Mathematics is regarded chiefly as a tool to be used in the study of science; hence those subjects are taken up, which art aseful in science. Speed, accuracy, and quick methods of solving are drilled on, rather than the more difficult and less useful principles. In algebra, the work of the first year, through fractional equations is reviewed, because many of the pupils taking this course have had trouble with their first year algebra; then involution, evolution, and simultaneous equations are considered, and also a little work with surds and exponents. In geometry lines, angles, triangles, circles, quadrilaterals, constructions, plotting curves, and proportion are taken up. With all these mathematical subjects some problem in science is first given, for the solution of which the mathematics is required.

Each subject in science is brought up by means of experiments, either by the pupils or by the teacher, which illustrate the principle in physics to be studied and gives a basis on which to work. In applying the principle the need of some subject in algebra or geometry is realized, which subject is then given and applied at once on the problem at hand.

An example will best show how the work in physics and mathe- 
matics can be combined in experiments and problems. On the first day about a dozen different objects, such as balances, motors; galvanometers, lenses, and various other pieces of apparatus, were placed on the tables. The pupils were told to look around for five minutes and then describe the three most interesting things they saw. Among the objects were two jars, one of water and the other of mercury, each containing an iron weight. About two thirds of the class noted the iron weight floating on the mercury as one of their three most interesting objects, so we started in to find the explanation. A little questioning brought out the need of being able to weigh and to measure the water and the mercury, which led to the metric system. After this, the subject of density was studied, being preceded by suitable experiments and being brought up by the consideration of the weight of a cubic centimeter of other substances than water. Working density problems, using the formula, brought in the need of algebra in the solution of fractional equations, so this subject was taken up in algebra, after first reviewing the subjects usually coming before fractional equations. Then followed specific gravity and the relation between the loss in weight of a body in a liquid and the weight of the liquid displaced, which explained the floating of the iron in the mercury.

Similarly, the length of object and of image formed by a lens or Charles' Law can be used for applications of a direct ratio; Boyle's Law for an inverse ratio; the inclined plane and heights of objects and lengths of shadows for similar triangles, which bring in the finding of the third side of a triangle. when the other two are given, which in turn brings in involution and evolution. Similar triangles, of course, bring in also the direct ratio. These suffice to suggest some of the ways in which physics and mathematics may be correlated, the science subjects being grouped according to the mathenatical principles which are used in solving them.

Some may object to a general science course like this, because it is planned for the second year, believing it ought to be in the first year. However, it would be perfectly possible to have such a course in the first year along with the first year algebra; that is, two separate courses, as there would not be time in one course to cover all the elements of algebra and the science besides. The two courses could be worked together, especially if the same teacher had both. 
Another objection will come from those who plan a general science course in order that the pupil who leaves school in the first or second year may get some acquaintance with scientific facts. Instead of planning the course for the benefit of just such a pupil, why not plan to prevent his leaving school? This can be done in one way by helping him in his mathematics, letting him pass off a condition in first year algebra by taking a course of science and mathematics combined. If the real causes of so many pupils becoming discouraged and leaving school could be known, trouble with mathematics, I venture, would be found to be one of the most common. A course of elementary physics and mathematics combined would be well worth while, if it would save some, if not all, of these pupils for the school.

\section{CRYSTALIIZATION.}

\section{By Franklin T. Jones, University School, Cleveland.}

The growth of crystals is a fascinating thing to watch. Usually the operation is, of necessity, carried on upon such a small scale that only one or two students can observe it at a time and, besides, to get good crystals, the growth is too slow to watch without great loss of time. It is possible to perform this experiment very simply and to show it to a whole class at a time at any place where a stereopticon is available.

Make a saturated hot solution of common salt, or of any substance whose crystals it is desired to observe. Place a drop or two on a clean glass plate, warm the plate slightly and place it either in front of the condensers as though it were a slide, or, better, place it on the stage of the vertical projector. Evaporation will take place very rapidly and the crystals will form by the time the teacher can explain what he intends to show.

Exceptionally beautiful effects are formed in sodium chloride solution. The cubical form of the crystals, the step construction, growth from the inside outward, dispersion effects showing colors, bright diagonals due to dispersion probably, etc., are all shown within a few minutes. The pattern is changing continually so there is no opportunity for a moment's lack of interest.

The experiment described is not new but the writer has not seen it previously explained in the columns of SCHOOL SCIENCE and Mathematics. 